\title{
Human umbilical cord blood-derived mesenchymal stem cells improve glucose homeostasis in rats with liver cirrhosis
}

\author{
KYUNG HEE JUNG ${ }^{1}$, YUN-KYUNG UHM ${ }^{1}$, YUN JEONG LIM ${ }^{2}$ and SUNG-VIN YIM ${ }^{1}$ \\ ${ }^{1}$ Department of Pharmacology, School of Medicine, Kyung Hee University, Seoul 130-701; ${ }^{2}$ Department of Internal Medicine, \\ Dongguk University Ilsan Hospital, Dongguk University, Goyang, Republic of Korea
}

Received January 21, 2011; Accepted March 29, 2011

DOI: 10.3892/ijo.2011.1016

\begin{abstract}
Disturbance of glucose metabolism is a common feature in liver cirrhosis which is associated with insulin resistance and is an established risk factor for disease progression and survival in patients with chronic liver diseases. We investigated whether umbilical cord blood-derived mesenchymal stem cells (HMSCs) have an effect on the expression of molecules responsible for glucose utilization and hepatic gluconeogenesis, focusing on the insulin signaling pathway in rats with liver cirrhosis. Rats received a dose of $\mathrm{CCl}_{4}(100 \mu \mathrm{l} / 100 \mathrm{~g} \mathrm{4:1}$ in corn oil) thrice-weekly. HMSCs were infused at 4 weeks after induction of liver cirrhosis by $\mathrm{CCl}_{4}$. Infusion of HMSCs improved insulin resistance which was associated with increased glucose levels and decreased insulin sensitivity in $\mathrm{CCl}_{4}$-induced cirrhotic rats. HMSCs increased activities in the proximal part of the insulin signaling cascade, as evidenced by increased expression of key enzymes such as phosphatidylinositol-3-kinase (PI 3-kinase), protein kinase B (PKB), protein kinase $\mathrm{C}-\zeta(\mathrm{PKC}-\zeta)$, and the decrease of glycogen synthase kinase 3 (GSK-3) compared to $\mathrm{CCl}_{4}$-induced liver cirrhotic rats. We also observed that glucose-6-phosphatase (G-6-P) and phosphoenolpyruvate kinase (PEPCK), two hepatic enzymes involved in gluconeogenesis were strongly decreased over $40-50 \%$ after infusion of HMSCs. Taken together, our results showed that HMSCs could improve insulin resistance in $\mathrm{CCl}_{4}$-induced liver cirrhosis, thereby contributing to glucose homeostasis.
\end{abstract}

\section{Introduction}

The liver plays a pivotal role in nutrient and hormone metabolism. In physiological conditions, hepatocytes are also the main site of hepatic glucose metabolism. Glucose intolerance is well-

Correspondence to: Dr Sung-Vin Yim, Department of Pharmacology, School of Medicine, Kyung Hee University, Hoegi-dong, Dongdaemun-gu, Seoul 130-701, Republic of Korea

E-mail: 94princess@hanmail.net

E-mail: ysvin@khu.ac.kr

Key words: umbilical cord bloods, mesenchymal stem cell, insulin resistance, phosphatidylinositol-3-kinase, glucose-6-phosphatase, glycogen synthase kinase 3 established feature of advanced liver cirrhosis that may result from excess glucose production and impaired glucose utilization $(1,2)$. These phenomena are closely associated with insulin resistance (3). Insulin regulates blood glucose primarily by stimulating glucose uptake into liver, muscle, and adipose tissue and by inhibiting hepatic glucose production. In type 2 diabetes, most of the intracellular actions of insulin are reduced or absent $(4,5)$, yet the lesions underlying insulin resistance is not clear. To find ways to solve insulin resistance, research has focused on the insulin-regulated signaling pathway that normally mediate glucose production or glucose utilization and that connect insulin receptor (IR) to the proteins that directly mediate each action of insulin. The IR is localized not only on the surface of the hepatocytes, but also on the other liver cells. The insulin binding to IRs causes the autophosphorylation of the receptor on intracellular tyrosine residues, followed by the activity phosphatidylinositol 3-kinase (PI 3-kinase). Next, PI 3-kinase activates protein kinase B (PKB) or protein kinase $\mathrm{C}-\zeta(\mathrm{PKC}-\zeta)$, which are PI 3 -kinase downstream substrates (6). Also, the activation of PKB leads to GSK-3 phosphorylation and activates glycogen synthase $(7,8)$. In addition, insulin regulates glucose-6-phosphatase (G-6-P) and phosphoenolpyruvate kinase (PEPCK), insulinresponsive proteins $(9,10)$. Numerous studies have suggested that the inability of insulin to regulate the rate-controlling gluconeo-genesis enzymes such as G-6-P and PEPCK may contribute to glucose intolerance $(11,12)$.

In the past 10 years, there have been substantial developments in stem cell research and the transplantation of these cells now holds great promise for regenerative medicine. Among stem cells, human umbilical cord blood (HUCB) has emerged as an attractive tool for cell-based therapy. HUCB are capable of differentiating into cells of different connective tissue lineages, such as bone, cartilage, adipose, and islets tissues (13-15). Mesenchymal stem cells (MSCs) are highly proliferating and they have been demonstrated to have potential not only for the various cells of mesodermal origin, but also for ectodermal neural cells and endodermal hepatic cells (16-18). The most common source of MSCs is bone marrow (BM), but aspirating BM from a patient is an invasive and uncomfortable procedure. In addition, it has been demonstrated that the number and differentiating potential of BM-derived MSCs decreased with age (19). Therefore, HUCB is of significant value as good source of MSCs. Indeed, it was 
reported that HUCB-derived MSC (HMSCs) have multilineage differentiation activity rather than BM-derived MSC (20). Recently, numerous studies have ascribed not only potent tissue regeneration and repair but also anti-inflamatory effects of HMSCs in various diseases such as kidney disease, lung injury, hypoxia-induced brain injury, and liver cirrhosis (21-24). Especially, HMSCs have been explored both as modulators of the immune response in type I diabetes and as potential sources of insulin-positive cells (25-27). However, most HMSC studies on diabetes have focused on insulin resistance induced from pancreas abnormality. There have been no reports on the effect of HMSCs on insulin sensitivity/ resistance and impaired glucose homeostasis induced from liver cirrhosis.

This study was undertaken to investigate whether HMSCs have an effect on decreased cellular glucose uptake and increased glucose production caused by insulin resistance in $\mathrm{CCl}_{4}$-induced liver cirrhotic rats. To test these effect of HMSCs, we investigated expression of PI 3-kinase, PKB, PKC- $\zeta$, GSK-3, G-6-P and PEPCK, which are known insulinmediated molecules.

\section{Materials and methods}

HMSC preparation. HUCB samples were harvested (Seoul Cord Blood Bank, Seoul, Korea) from term and pre-term deliveries at the time of birth with the mothers' consent. Blood samples were processed within $24 \mathrm{~h}$ from collection. The mononuclear cells were separated from HUCB using Ficoll-Paque ${ }^{\mathrm{TM}}$ PLUS (Amersham Bioscience, Uppsala, Sweden) and were suspended in culture medium (DMEM; Gibco, Grand Island, NY) containing 15\% FBS, $100 \mathrm{U} / \mathrm{ml}$ penicillin, $100 \mathrm{mg} / \mathrm{ml}$ streptomycin, $2 \mathrm{M} \mathrm{L}$-glutamine and $1 \mathrm{M}$ sodium pyruvate. The cells were then seeded at a density of $1 \times 10^{6}$ cells $/ \mathrm{cm}^{2}$ in culture flasks. After 7 days of culture, suspended cells were removed and adherent cells were additionally cultured (MSCs). MSCs were maintained at $37^{\circ} \mathrm{C}$ in a humidified atmosphere containing $5 \%$ carbon dioxide, with a change of culture medium every 3-4 days. Approximately $50-60 \%$ of confluent cells were detached with $0.1 \%$ trypsinEDTA and replaced at a density of $2 \times 10^{3}$ cells $/ \mathrm{cm}^{2}$ in culture flasks. To label cells with CM-1,1'-dioctadecyl-3,3,3'-testramethylindo-carbocyanine perchloride (CM-DiI; Invitrogen, Carlsbad,CA), $1 \mu \mathrm{g}$ of CM-DiI per microliter of dimethylsulfoxide (DMSO; Sigma, Canton, MA) stock solution was added to HMSCs suspensions at $1 \times 10^{6} \mathrm{cell} / \mathrm{ml}$ in Plasmalyte A (Baxter) to yield a final concentration of $1 \mu \mathrm{g}$ of CM-DiI solution $/ \mathrm{ml}$. This suspension was incubated at $37^{\circ} \mathrm{C}$ for $5 \mathrm{~min}$, then at $4^{\circ} \mathrm{C}$ for 15 min with occasional mixing and the HMSCs labeled with CM-DiI were washed 3 times.

$\mathrm{CCl}_{4}$-induced liver cirrhosis model. Male Sprague-Dawley rats (6-week old, 180-200 g) were used for the experiments. These animals were housed in an air-conditioned room at $25^{\circ} \mathrm{C}$ with a $12 \mathrm{~h}$ dark/light cycle. All animals received human care during the study with unlimited access to chow and water. Liver cirrhosis was induced by intraperitoneal (i.p.) administration of $\mathrm{CCl}_{4}(4: 1$ olive oil) at a dose of $0.1 \mathrm{ml} / 100 \mathrm{~g}$ body weight thrice-weekly. The same volume of olive oil alone was used as control. Liver cirrhosis was determined by sacrificing 3-6 rats with histopathology per week. After 8 weeks, $\mathrm{CCl}_{4}$-induced liver cirrhosis was identified using morphologic method by special pathologist. Eighty rats were randomly divided at 8 weeks into four groups: $\mathrm{HMSCs} / \mathrm{CCl}_{4}$ $(n=20)$; saline/ $\mathrm{CCl}_{4}(\mathrm{n}=20)$, HMSCs was infused a dose of $1 \times 10^{6}$ cells labeled with CM-DiI and saline was infused the same volume per rat by tail vein. Blank controls, HMSCs/olive $(n=20)$ and saline/olive $(n=20)$, were designed to infuse saline and HMSCs of the same volume at 8 weeks after olive injection. At 4 weeks after infusion of HMSCs, rats were sacrificed and venous blood was collected.

Pathology. Liver samples were fixed in $10 \%$ buffered formaldehyde solution, processed by the paraffin slice technique. Sections of $4 \mu \mathrm{m}$ thick were stained with hematoxylin and eosin (H\&E) staining for routine histology, and Masson's trichrome (MT) staining for collagen. For H\&E staining, sections were stained with hematoxylin for $3 \mathrm{~min}$, washed, and stained with $0.5 \%$ eosin for $3 \mathrm{~min}$. After an additional washing step with water, the slides were dehydrated in 70,96 , and $100 \%$ ethanol, and then in xylene. The degree of liver damage was examined in a blind manner by a pathologist under a light microscope (Olympus, Hamburg, Germany).

Oral glucose tolerance test. At 4 weeks after HMSCs infusion in $\mathrm{CCl}_{4}$-induced liver cirrhosis rats, an oral glucose tolerance test (OGTT) was performed after an overnight fast. D-glucose $(3.0 \mathrm{~g} / \mathrm{kg}$ body weight) was administered by gavage and blood samples were obtained by tail bleeding at 0 (before glucose administration), 30, 60, and $120 \mathrm{~min}$ after the glucose load. Blood glucose levels (Haemoglucotest, 1-44 and Reflolux $\Pi$ reflectance meter, Boehringer-Mannheim, Mannheim, Germany) and serum insulin concentrations were measured with rat ELISA kit (Merocida AB, Uppsala, Sweden) (28).

Biochemical analysis. Alanine aminotransferase (ALT), aspartate aminotransferse (AST), albumin, total protein, total bilirubin, alkaline phosphatase (ALP), hyaluronic acid, and laminin were analyzed by Green Gross Reference Lab (Seoul, Korea).

Immunoprecipitation. Immunoprecipitation was performed as follows (29). After homogenizing liver tissue with $1 \mathrm{ml}$ of lysis buffer ( $\mathrm{pH} 7.5,50 \mathrm{M}$ Tris- $\mathrm{HCl}, 150 \mathrm{M} \mathrm{NaCl}, 1 \mathrm{M} \mathrm{MgCl}_{2}$, $1 \mathrm{M} \mathrm{CaCl}_{2}, 1 \mathrm{M}$ sodium orthovanadate, $100 \mathrm{M} \mathrm{NaF}, 1 \mathrm{M}$ EGTA, $1 \%$ Triton X-100, $10 \%$ glycerol, leupeptin $(5 \mu \mathrm{g} / \mathrm{ml})$ and $1 \mathrm{mmol} / 1$ phenylmethylsulfonyl fluoride) on ice, it was washed twice with ice-cold PBS. The homogenized liver tissues were then centrifuged at $15,000 \mathrm{~g}$ for $15 \mathrm{~min}$ at $4^{\circ} \mathrm{C}$ and supernatant was harvested. For immunoprecipitation, $20 \mu \mathrm{l}$ of anti-phosphotyrosine antibody agarose beads was incubated with supernatant containing $500 \mu \mathrm{g}$ of protein for $1 \mathrm{~h}$ at $4^{\circ} \mathrm{C}$. Immunoprecipitates were washed three times with PBS containing $1 \%$ Nonidet P-40, three times with $100 \mathrm{M}$ Tris- $\mathrm{HCl} \mathrm{pH} 7.5$ containing $500 \mathrm{M} \mathrm{LiCl}_{2}$ and finally twice with $25 \mathrm{M}$ Tris- $\mathrm{HCl}$ containing $100 \mathrm{M} \mathrm{NaCl}$ and $1 \mathrm{M}$ EDTA.

PI 3-kinase assay. Crude PI 3-kinase was obtained by immunoprecipitation with antiphosphotyrosine antibody. Tissue lysates (500 $\mu \mathrm{g}$ protein) were incubated with $20 \mu \mathrm{l}$ of antiphosphotyrosine antibody agarose beads. After washing, the 
A

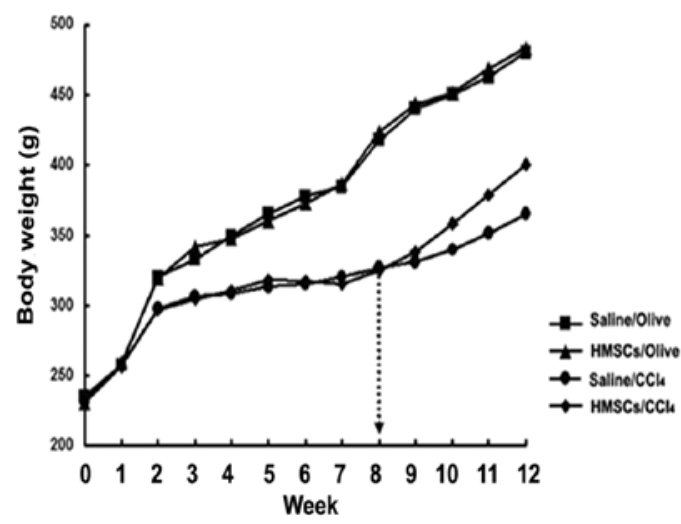

B

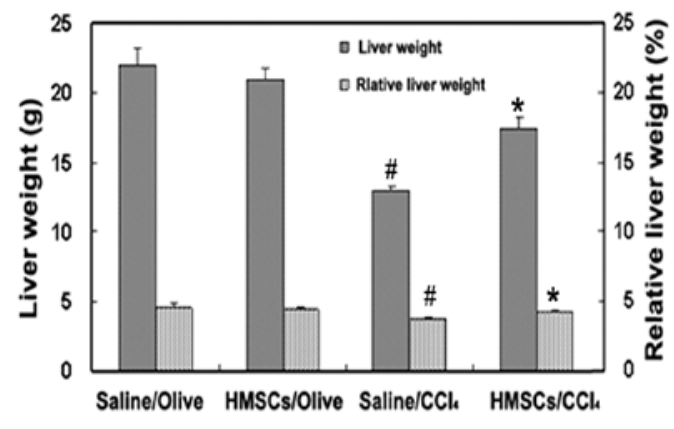

Figure 1. Effect of HMSCs on the body and liver weights in $\mathrm{CCl}_{4}$-induced liver cirrhosis rats. (A) Average weight change of rats induced with $\mathrm{CCl}_{4}$ for 12 weeks. (B) Liver weights and relative liver weight in $\mathrm{CCl}_{4}$-induced liver cirrhosis. $\mathrm{HMSCs}$ and saline were injected after the $\mathrm{CCl}_{4}$ induction for 8 weeks by tail vein. Values are expressed as the mean $\pm \mathrm{SD}(\mathrm{n}=20) .{ }^{\#} \mathrm{p}<0.05$ vs. saline/olive, ${ }^{*} \mathrm{p}<0.05$ vs. saline $/ \mathrm{CCl}_{4}$.

immunoprecipitates with PI3-kinase activity were resuspended in $100 \mu \mathrm{l}$ of kinase assay buffer $(20 \mathrm{M}$ Tris- $\mathrm{HCl}, 75 \mathrm{M} \mathrm{NaCl}$, $10 \mathrm{M} \mathrm{MgCl}_{2}, 200 \mu \mathrm{g} / \mathrm{ml}$ phosphatidylinositol, $1 \mathrm{M}$ EGTA, $20 \mu \mathrm{M}$ ATP, $\left.10 \mu \mathrm{Ci}\left[\gamma^{-32} \mathrm{P}\right]-\mathrm{ATP}\right)$ and incubated for $30 \mathrm{~min}$ at room temperature with constant shaking. PI 3-kinase activity was measured by the phosphorylation of PI. The reaction was stopped by the addition of $100 \mu 11 \mathrm{M} \mathrm{HCl}$ and the reaction products were extracted with $200 \mu \mathrm{l}$ chloroform:methanol (1:1). The samples were centrifuged and the lower organic phase was harvested and applied to a silica gel thin layer chromatography (TLC) plate (Merck, Aichach, Germany) coated with $1 \%$ potassium oxalate. TLC plates were developed in chloroform : methanol : ammonium hydroxide : water (60:47:11.3:2), dried, and visualized by autoradiography.

Western blotting. Liver protein $(40 \mu \mathrm{g})$ was separated by SDS-PAGE gel electrophoresis and transferred to nitrocellulose membrane (Schleicher \& Schuell, Middlesex, UK). The membrane was blocked with $5 \%$ skim milk in $10 \mathrm{M}$ Tris- $\mathrm{HCl}$ containing $150 \mathrm{M} \mathrm{NaCl}$ and $0.5 \%$ Tween-20 (TBS-T). After washing with TBS-T, the membrane was then incubated with primary antibodies (1:500) recognizing p-PKB, p-PKC- $\zeta$, p-GSK-3, G-6-P, and PEPCK (Cell Signaling, Beverly, MA). After washing with TBS-T, horseradish peroxidase-HRPconjugated secondary antibody (New England Biolabs, Beverly, MA, 1:1000 in TBS-T) was applied to the membrane and the blot was developed using an enhanced chemiluminescence detection kit (Amersham, Piscataway, NJ).

Statistical analysis. Results were expressed as the mean \pm SD. Statistical analysis was performed using one-way ANOVA and post hoc test was performed for multiple comparisons. A $\mathrm{p}<0.05$ or 0.01 was taken to indicate statistical significance. Statistical calculations were performed using SPSS software Windows (Version 10.0; SPSS, Chicago, IL).

\section{Results}

Body and liver weight. Rats given $\mathrm{CCl}_{4}$ showed slower weight gain than rats with olive oil alone (Fig. 1). The average weight of rats injected with $\mathrm{CCl}_{4}$ for 8 weeks was $100-150 \mathrm{~g}$ lower than rats with olive oil alone. The mortality rates were about $10 \%$ in rats treated with $\mathrm{CCl}_{4}$ after 8 weeks, while the olive oil-injected rats were all alive. Also, the final liver weight in the saline $/ \mathrm{CCl}_{4}$ group was $56 \%$ of the saline/olive control. However, liver weights in the $\mathrm{HMSCs} / \mathrm{CCl}_{4}$ group were $78 \%$ of the saline/olive control. This result showed that HMSC infusion prevented $\mathrm{CCl}_{4}$-induced loss of liver weight. A significant increase in relative liver weight $(\mathrm{p}<0.05)$ occurred after $\mathrm{HMSC}$ infusion in $\mathrm{CCl}_{4}$-induced liver cirrhosis. Relative liver weights in $\mathrm{HMSCs} / \mathrm{CCl}_{4}$ group were $91 \%$ of the saline/ olive control.

Pathology. Liver cirrhosis in the rats was evaluated by two histological methods: H\&E and MT staining. The results from two methods showed the same pattern. The histological analyses of the livers in saline/olive and HMSCs/olive groups showed normal architecture (Fig. 2). $\mathrm{CCl}_{4}$ injection for 8 weeks induced extensive liver cirrhosis/fibrosis, as evidenced by both qualitative and quantitative histopathological examination. As shown in Fig. 2, liver morphology of $\mathrm{CCl}_{4}$-induced cirrhotic rats presented disruption of tissue architecture, extension of fibers, large fibrous septa formation, pseudo lobe separation and collagen accumulation. The extent of fibrosis was remarkably reduced after infusion of HMSCs. In both H\&E and MT staining, the histological structure was obviously improved after $\mathrm{HMSC}$ infusion in $\mathrm{CCl}_{4}$-induced liver cirrhotic rat compared to the $\mathrm{CCl}_{4}$ induction group.

Biochemical analysis. Serum markers for liver function such as ALT and AST were significantly decreased after HMSC infusion in $\mathrm{CCl}_{4}$-induced liver cirrhosis rats (Table $\mathrm{I}, \mathrm{p}<0.05$ ). However, ALT and AST in saline/ $\mathrm{CCl}_{4}$ group continued to be elevated compared to saline/olive and HMSCs/olive groups. In addition, serum total protein and albumin concentrations were decreased in saline $/ \mathrm{CCl}_{4}$ group and stayed low, while serum total protein and albumin in $\mathrm{HMSCs} / \mathrm{CCl}_{4}$ group was significantly increased, compared to saline $/ \mathrm{CCl}_{4}$ group $(\mathrm{p}<0.05)$. ALP and total bilirubin levels were significantly decreased in $\mathrm{HMSCs} / \mathrm{CCl}_{4}$ group, as compared with saline/ $\mathrm{CCl}_{4}$ group 


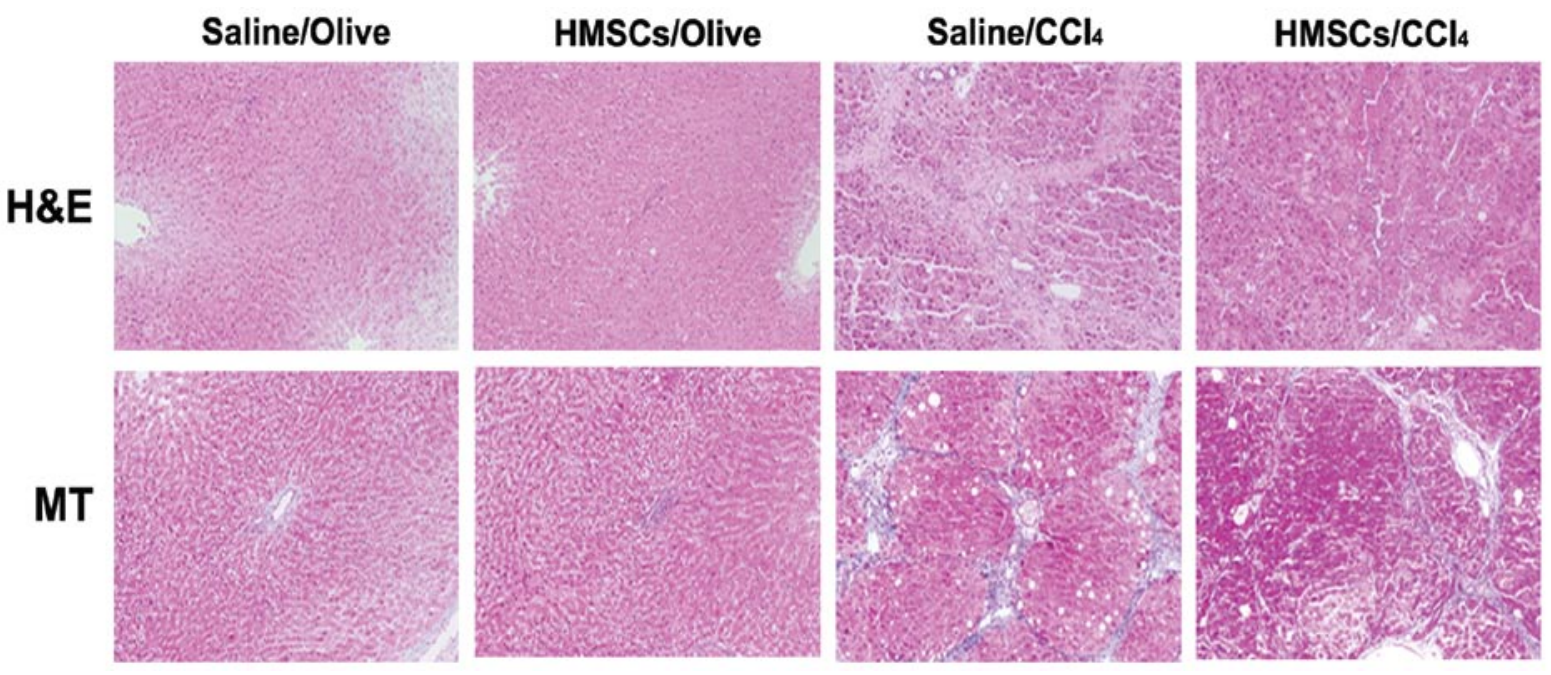

Figure 2. Histological analysis of liver sections. Liver sections were stained using H\&E and MT. Original magnification x200.

A

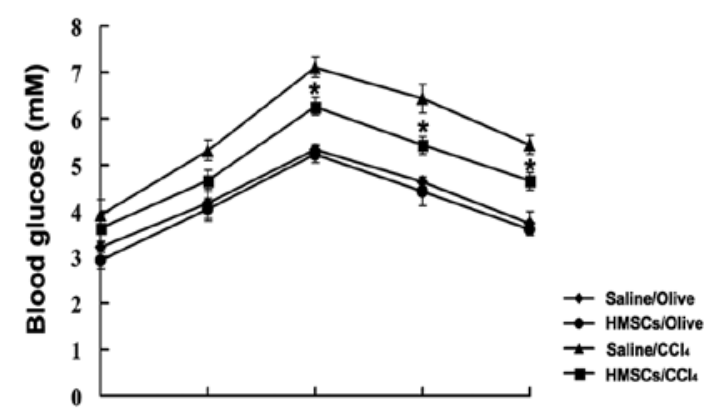

B

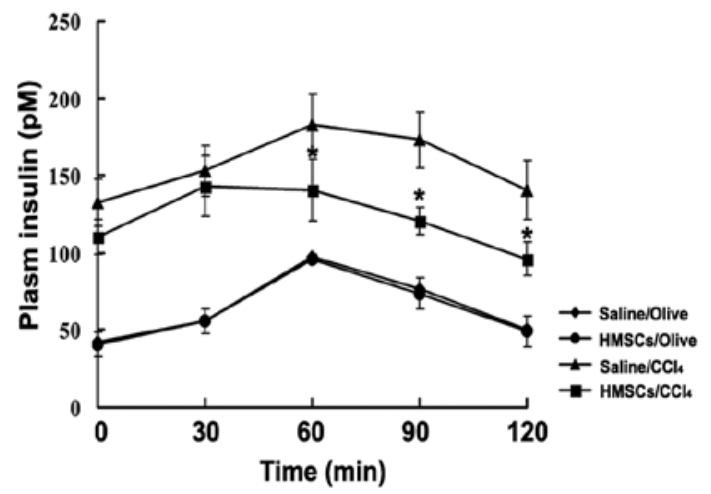

Figure 3. Plasma glucose (A) and insulin levels (B) during oral glucose tolerance test after $\mathrm{HMSC}$ infusion in rat $\mathrm{CCl}_{4}$-induced liver cirrhosis. Plasma glucose levels were elevated during the oral glucose tolerance test, and an oral glucose load led to increases in insulin levels in control, cirrhosis, and HMSCs infusion groups. Values are expressed as the mean $\pm \mathrm{SD}^{*} \mathrm{p}<0.05 \mathrm{vs}$. saline/ $\mathrm{CCl}_{4}$.

$(\mathrm{p}<0.05)$. Hyaluronic acid and laminin levels, indicators of fibrosis/cirrhosis, were decreased in $\mathrm{HMSCs} / \mathrm{CCl}_{4}$ group and showed significant difference, compared to saline/ $\mathrm{CCl}_{4}$ group $(\mathrm{p}<0.05)$.

Insulin and glucose level after HMSC infusion in liver cirrhotic rats. To identify insulin and glucose intolerance both in $\mathrm{CCl}_{4}$-induced liver cirrhotic rats and after HMSC infusion in $\mathrm{CCl}_{4}$-induced liver cirrhotic rats, we measured insulin and glucose levels on $0,30,60,90$, and 120 min after oral glucose load. As shown in Fig. 3, $\mathrm{CCl}_{4}$-induced liver cirrhotic rats (saline/ $\mathrm{CCl}_{4}$ ) showed a tendency to elevate plasma insulin levels up to $60 \mathrm{~min}$ after an oral glucose load, while decreased slowly insulin levels from 90 to $120 \mathrm{~min}$. However, insulin levels after HMSC infusion in $\mathrm{CCl}_{4}$-induced liver cirrhotic rats ( $\mathrm{HMSCs} / \mathrm{CCl}_{4}$ ) were decreased significantly from 60 to $120 \mathrm{~min}$, compared to saline/ $\mathrm{CCl}_{4}(\mathrm{p}<0.05)$. Similar to insulin levels, glucose levels in saline/ $\mathrm{CCl}_{4}$ were increased from 30 to $120 \mathrm{~min}$, and showed remarkable increase at $60 \mathrm{~min}$, compared to control $(\mathrm{p}<0.05)$. However, glucose levels of $\mathrm{HMSCs} / \mathrm{CCl}_{4}$ group showed significant decrease from 60 to $120 \mathrm{~min}$, compared to saline/ $\mathrm{CCl}_{4}(\mathrm{p}<0.05)$. These results indicate that HMSC infusion is effective on glucose intolerance and insulin resistance caused by liver cirrhosis.

Insulin signaling activity after HMSCs infusion in liver cirrhotic rats. To investigate the possible involvement of HMSCs on insulin-regulated signaling molecules in $\mathrm{CCl}_{4}$-induced liver cirrhotic rats, we assessed activity of PI 3-kinase and expressions of PKB and PKC- $\zeta$ using PI 3-kinase assay/ Western blotting, respectively. As shown in Fig. 4, phosphatidylinositol-3-phosphate (PI-3-P), which is formed by PI 3-kinase activity, was markedly decreased in saline/ $\mathrm{CCl}_{4}$, compared to saline/olive $(1.3 \pm 0.31, \mathrm{p}<0.05)$. However, it was obviously increased in $\mathrm{HMSCs} / \mathrm{CCl}_{4}$, compared to saline/ $\mathrm{CCl}_{4}$ after HMSC infusion $(3.2 \pm 0.23, \mathrm{p}<0.05)$. The phosphorylation of PKB and PKC- $\zeta$, downstream of PI 3-kinase, also were decreased in saline $/ \mathrm{CCl}_{4}$, whereas phosphorylation of these was significantly increased in $\mathrm{HMSCs} / \mathrm{CCl}_{4}$ (Fig 5 , p <0.05). We also investigated whether HMSC infusion influenced the expression of GSK-3 in $\mathrm{CCl}_{4}$-induced liver cirrhotic rats. As a result, the phosphorylation level of GSK-3 in $\mathrm{HMSCs} / \mathrm{CCl}_{4}$ was increased $>30 \%$ after HMSC infusion, compare to saline/ $\mathrm{CCl}_{4}(\mathrm{p}<0.05)$.

Hepatic gluconeogenic enzymes after HMSC infusion in liver cirrhotic rats. Liver plays a prominent role in controlling blood glucose levels through hepatic glucose production. Thus, we investigated the expression of G-6-P and PEPCK, 
Table I. Effects of HMSCs on serum parameters in rat $\mathrm{CCl}_{4}$-induced liver cirrhosis.

\begin{tabular}{lcccr}
\hline & \multicolumn{3}{c}{ Groups } \\
\cline { 2 - 5 } Parameter & Saline/olive & HMSCs/olive & Saline/CCl & HMSCs $_{4}$ \\
\hline ALC $($ Karmen $/ \mathrm{ml})$ & $49.12 \pm 8.01$ & $48.16 \pm 7.51$ & $300.17 \pm 18.12^{\mathrm{a}}$ & $194.33 \pm 8.41^{\mathrm{b}}$ \\
AST $($ Karmen/ml) & $44.17 \pm 9.23$ & $47.28 \pm 6.35$ & $350.21 \pm 36.39^{\mathrm{a}}$ & $260.14 \pm 18.16^{\mathrm{b}}$ \\
Albumin $(\mathrm{g} / \mathrm{dl})$ & $3.42 \pm 0.07$ & $3.52 \pm 0.09$ & $2.24 \pm 0.12^{\mathrm{a}}$ & $3.03 \pm 0.14^{\mathrm{b}}$ \\
Total protein $(\mathrm{g} / \mathrm{dl})$ & $7.13 \pm 0.16$ & $6.91 \pm 0.13$ & $4.48 \pm 0.18^{\mathrm{a}}$ & $5.92 \pm 0.24^{\mathrm{b}}$ \\
ALP $(\mathrm{U} / \mathrm{l})$ & $174.23 \pm 22.43$ & $181.66 \pm 33.21$ & $736.61 \pm 62.43^{\mathrm{a}}$ & $399.88 \pm 51.36^{\mathrm{b}}$ \\
Total bilirubin $(\mathrm{mg} / \mathrm{dl})$ & $0.21 \pm 0.03$ & $0.24 \pm 0.03$ & $2.84 \pm 0.25^{\mathrm{a}}$ & $1.75 \pm 0.14^{\mathrm{b}}$ \\
Hyaluronic acid $(\mathrm{ng} / \mathrm{ml})$ & $46.25 \pm 2.11$ & $44.31 \pm 2.27$ & $568.42 \pm 25.11^{\mathrm{a}}$ & $267.91 \pm 28.22^{\mathrm{b}}$ \\
Laminin $(\mu \mathrm{g} / \mathrm{ml})$ & $137.91 \pm 30.32$ & $138.63 \pm 20.58$ & $780.01 \pm 39.11^{\mathrm{a}}$ & $359.24 \pm 50.77^{\mathrm{b}}$ \\
\hline
\end{tabular}

All biomarkers in $\mathrm{CCl}_{4}$-induced group were improved after HMSCs infusion. ALT, alanine aminotransferase; AST, aspartate aminotransferase; ALP, alkakine phosphatase. Values are expressed as mean $\pm \mathrm{SD}$. ${ }^{\mathrm{a}} \mathrm{p}<0.05$ vs. saline/olive; and ${ }^{\mathrm{b}} \mathrm{p}<0.05$ vs. saline/CCl ${ }_{4}$, respectively.

PI-3-P
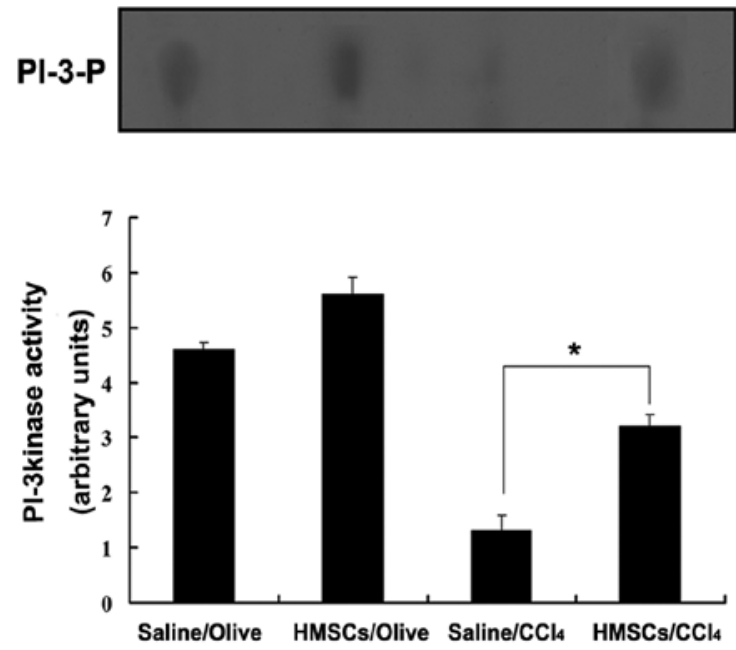

Figure 4. Effect of HMSCs on phosphatidylinositol 3-kinase (PI 3-kinase) activity in rat with $\mathrm{CCl}_{4}$-induced liver cirrhosis. PI 3-kinase activity was measured in anti-phosphotyrosine immunocomplex. PI-3-P, phosphatidylinositol-3-phosphate. Values are expressed as the mean $\pm \mathrm{SD}^{*} \mathrm{p}<0.05$ vs. saline $/ \mathrm{CCl}_{4}$. which are rapidly inhibited at the transcriptional level by insulin in $\mathrm{CCl}_{4}$-induced liver cirrhotic rats (30). As expected, the expression of G-6-P and PEPCK in saline/CCl $\mathrm{Cl}_{4}$ was increased (Fig. 6). However, the expressions of G-6-P and PEPCK after HMSC infusion was remarkably decreased, compared to saline $/ \mathrm{CCl}_{4}(0.45 \pm 0.04$ and $0.39 \pm 0.01$ respectively, $\mathrm{p}<0.05)$. The results demonstrated that HMSCs decreased gluconeogenesis in $\mathrm{CCl}_{4}$-induced liver cirrhosis.

\section{Discussion}

This is the first study to show that HMSCs can improve insulin resistance and glucose intolerence in $\mathrm{CCl}_{4}$-induced liver cirrhotic rat model. Our results demonstrated that HMSCs inhibited hepatic gluconeogenesis by suppressing both G-6-P and PEPCK expressions and improve insulin resistance by increasing expressions of PI 3-kinase and PKB.

It is well established that cirrhotic subjects are glucose intolerant (31): 60-80\% display impaired glucose tolerance,
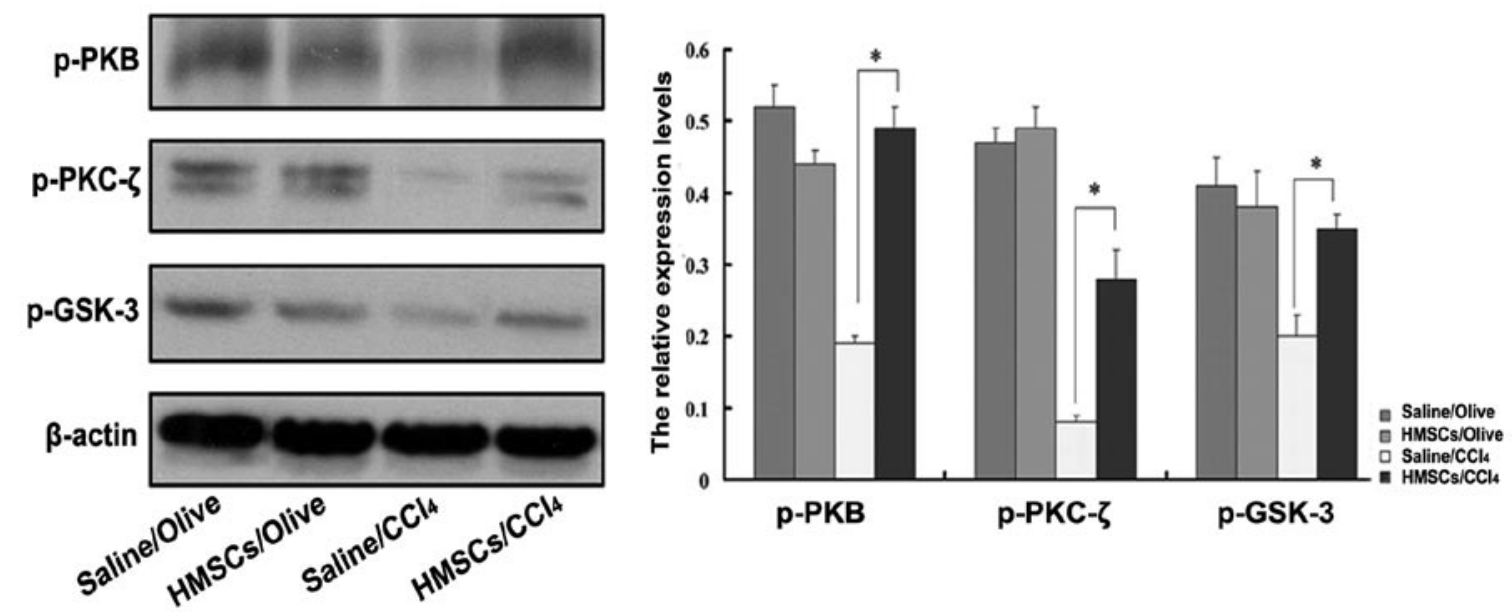

Figure 5. Effect of HMSCs on the phosphorylation of protein kinase B (p-PKB), protein kinase C- $\zeta$ (p-PKC- $\zeta$ ), and glycogen synthase kinase 3 (p-GSK-3) by Western blotting. Quantification of p-PKB, p-PKC- $\zeta$, and p-GSK-3 expressions was performed by densitometry analysis. Data are the mean \pm SD of p-PKB $/ \beta-$ actin, $\mathrm{p}$-PKC- $\zeta / \beta$-actin, and p-GSK-3/ $\beta$-actin at least three separate experiments. ${ }^{*} \mathrm{p}<0.05$ vs. saline $/ \mathrm{CCl}_{4}$. 

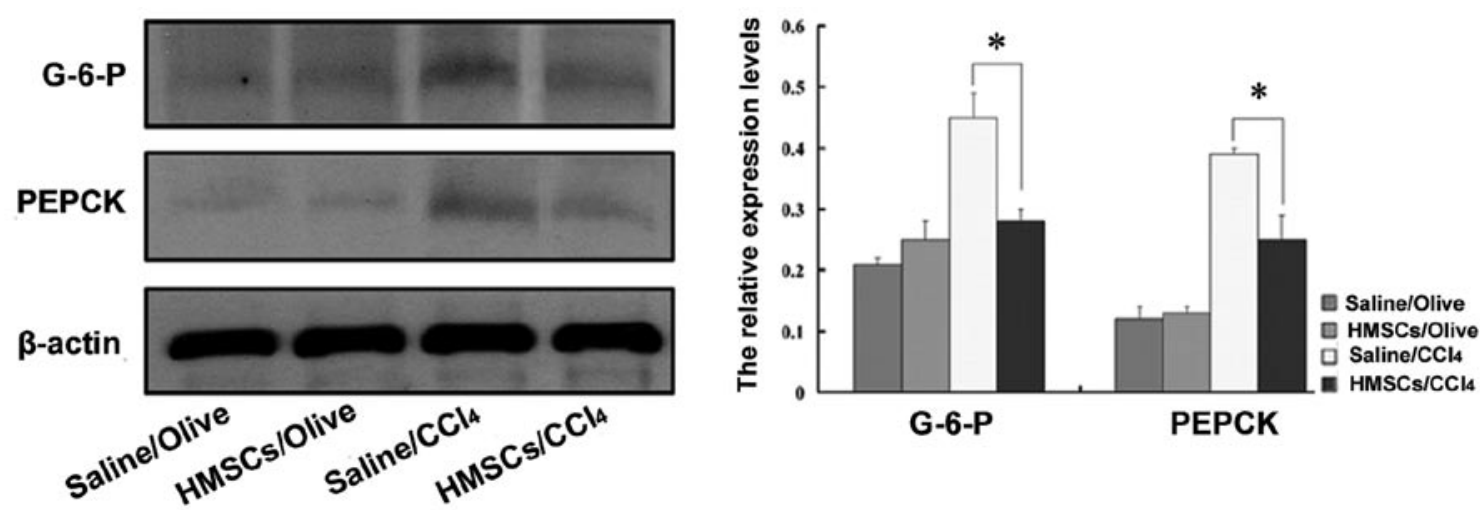

Figure 6. Effect of HMSCs on expressions of glucose-6-phosphatase (G-6-P) and phosphoenolpyruvate carboxykinase (PEPCK) by Western blotting. Quantification of G-6-P and PEPCK expression was performed by densitometry analysis. Data are the mean \pm SD of G-6-P/ $\beta$-actin PEPCK/ $\beta$-actin at least three separate experiments. " $\mathrm{p}<0.05$ vs. saline $/ \mathrm{CCl}_{4}$.

and $10-30 \%$ are anticipated to develop diabetes (32). Moreover, cirrhotic patients have insulin resistance because a rise of plasma glucose entails an increase of insulin secretion $(33,34)$. Insulin resistance has been defined as a subnormal biological response to a normal concentration of insulin (35). So to determine if cirrhotic animals were insulin resistant, we examined serum glucose and insulin concentration. High glucose and insulin levels were noted in $\mathrm{CCl}_{4}$-induced liver cirrhotic rats. However, the levels of glucose and insulin were decreased in cirrhosis rats after HMSCs infusion. This is similar to results of Hess et al reporting that bone-marrow derived stem cell improved glucose tolerance by reducing glucose levels in steptozotocininduced hyperglycemic mice (36). Furthermore, to identify whether HMSCs improve the insulin resistance associated with liver cirrhosis, we assessed the expression of proximal part of the insulin signaling cascade. Glucose is mediated by IRS-1, PI-3 kinase, and other molecules. The IRS-1 protein, once phosphorylated at distinct tyrosine residues, acts as docking site for PI-3kinase. PKB and PKC- $\zeta$ is PI-3 kinase downstream molecules mediated insulin-stimulated glucose (37). In our study, it was observed that HMSCs increased the phosphorylation of PKB and PKC- $\zeta$ by activating PI 3-kinase. It is known that phosphorylated PKB induces phosphorylation and inactivation of GSK-3. Hence, phosphorylation and inactivation of GSK-3 results in activation of glycogen synthase and increased glycogen synthesis. Although we did not measure glycogen synthesis in the liver, our results of Western blotting showed that the phosphorylation of GSK-3 is significantly increased in $\mathrm{CCl}_{4}$-induced cirrhotic rats after HMSCs infusion, compared with saline $/ \mathrm{CCl}_{4}$. Thus, these results revealed that HMSCs had a possibility to improve insulin resistance by phosphorylating and inactivating GSK-3 in $\mathrm{CCl}_{4}$-induced cirrhotic rats.

In addition, we focused on pathways controlling hepatic glucose production. Increased gluconeogenesis is a main source of increased hepatic glucose production and the inability of insulin to regulate the rate-controlling gluconeogenic enzymes may contribute to this problem. Representative two insulinresponsive molecules for regulation of hepatic gluconeogenesis are G-6-P and PEPCK $(9,38)$. G-6-P is a key enzyme in systemic glucose homeostasis, because it catalyzes the last biochemical reaction of glucose synthesis (39). In streptozotocin-induced diabetes animal models, hepatic G-6-P enzyme activity, protein and mRNA expression are increased about 4-fold (40). Also, it has been reported that the over-expression of PEPCK, which is a rate-determining step in gluconeogenesis, increased hepatic glucose in diabetic animal model (41). In our present study, the expression of PEPCK and G-6-P were reduced up to approximately 40 and $50 \%$ after $\mathrm{HMSCs}$ infusion in $\mathrm{CCl}_{4}$-induced liver cirrhosis group, respectively. In this regard, our results indicated that HMSCs were involved in gluconeogenesis by regulating expression of PEPCK and G-6-P in $\mathrm{CCl}_{4}$-induced liver cirrhotic rats.

In conclusion, we demonstrated that HMSCs improve insulin resistance by increasing PI 3-kinase, PKB, PKC- $\zeta$, and GSK-3 and alleviated gluconeogenesis by decreasing the expression of G-6-P and PEPCK in $\mathrm{CCl}_{4}$-induced liver cirrhosis rats. Our study suggests that HMSCs might be a valuable therapeutic tool in the treatment of insulin resistance caused by liver cirrhosis.

\section{Acknowledgements}

This work was supported by a grant from the Kyung Hee University in 2009 (KHU).

\section{References}

1. Bugianesi E, McCullough AJ and Marchesini G: Insulin resistance: a metabolic pathway to chronic liver disease. Hepatology 42: 987-1000, 2005.

2. Kruszynska YT, Meyer-Alber A and Darakhshan F: Metabolic handling of orally administered glucose in cirrhosis. J Clin Invest 91: 1057-1066, 1993.

3. Johnston DG, Alberti GM and Wright R: C-peptide and insulin in liver disease. Diabetes 27: 201-206, 1978.

4. De Fronzo RA: The triumvirate: beta-cell, muscle, liver. A collusion responsible for NIDDM. Diabetes 37: 667-687, 1988.

5. Paz K, Hemi R and Le Roith D: A molecular basis for insulin resistance. Elevated serine/threonine phosphorylation of IRS-1 and IRS-2 inhibits their binding to the juxtamembrane region of the insulin receptor and impairs their ability to undergo insulin-induced tyrosine phosphorylation. J Biol Chem 272: 29911-29918, 1997.

6. Virkamaki A, Ueki K and Kahn CR: Protein-protein interaction in insulin signaling and the molecular mechanisms of insulin resistance. J Clin Invest 103: 931-943, 1999.

7. Coghlan MP, Culbert AA and Cross DA: Selective small molecule inhibitors of glycogen synthase kinase-3 modulate glycogen metabolism and gene transcription. Chem Biol 7: 793-803, 2000. 
8. Cross DA, Alessi DR and Cohen P: Inhibition of glycogen synthase kinase-3 by insulin mediated by protein kinase B. Nature 378: 785-789, 1995.

9. Sutherland C, O'Brien RM and Granner DK: New connections in the regulation of PEPCK gene expression by insulin. Philos Trans R Soc Lond B Biol Sci 351: 191-199, 1996.

10. O'Brien RM and Granner DK: PEPCK gene as model of inhibitory effects of insulin on gene transcription. Diabetes Care 13: 327-339, 1990.

11. Hofmann CA, Edwards CW and Hillman RM: Treatment of insulin-resistant mice with the oral antidiabetic agent pioglitazone: evaluation of liver GLUT2 and phosphoenolpyruvate carboxykinase expression. Endocrinology 130: 735-740, 1992.

12. Valera A, Rodriguez-Gil JE and Bosch F: Vanadate treatment restores the expression of genes for key enzymes in the glucose and ketone bodies metabolism in the liver of diabetic rats. J Clin Invest 92: 4-11, 1993.

13. Palma CA, Lindeman R and Tuch BE: Blood into beta-cells: can adult stem cells be used as a therapy for Type 1 diabetes? Regen Med 3: 33-47, 2008

14. Sanchez-Ramos J: Stem cells from umbilical cord blood. Semin Reprod Med 24: 358-369, 2006.

15. Jager M, Wild A and Lensing-Hohn S: Influence of different culture solutions on osteoblastic differentiation in cord blood and bone marrow derived progenitor cells. Biomed Tech 48 : 241-244, 2003

16. Minguell JJ, Erices A and Conget P: Mesenchymal stem cells Exp Biol Med 226: 507-520, 2001

17. Sanchez-Ramos JR: Neural cells derived from adult bone marrow and umbilical cord blood. J Neurosci Res 69: 880-893, 2002.

18. Lee KD, Kuo TK and Whang-Peng J: In vitro hepatic differentiation of human mesenchymal stem cells. Hepatology 40: 1275-1284, 2004.

19. D'Ippolito G, Schiller PC and Ricordi C: Age-related osteogenic potential of mesenchymal stromal stem cells from human vertebral bone marrow. J Bone Miner Res 14: 1115-1122, 1999.

20. Jeong JA, Gang EJ and Hong SH: Rapid neural differentiation of human cord blood-derived mesenchymal stem cells. Neuroreport 15: 1731-1734, 2004

21. Chang JW, Hung SP, Wu HH, Wu WM, Yang AH, Tsai HL, Yang LY and Lee OK: Therapeutic effects of umbilical cord blood-derived mesenchymal stem cell transplantation in experimental lupus nephritis. Cell Transplant (In press).

22. Chang YS, Oh W, Choi SJ, Sung DK, Kim SY, Choi EY, Kang S, Jin HJ, Yang YS and. Park WS: Human umbilical cord bloodderived mesenchymal stem cells attenuate hyperoxia-induced lung injury in neonatal rats. Cell Transplant 18: 869-886, 2009.

23. Xia G, Hong X, Chen X, Lan F, Zhang G and Liao L: Intracerebral transplantation of mesenchymal stem cells derived from human umbilical cord blood alleviates hypoxic ischemic brain injury in rat neonates. J Perinat Med 38 215-221, 2010.

24. Jung KH, Shin HP, Lee S, Lim YJ, Hwang SH, Han H, Park HK, Chung JH and Yim SV: Effect of human umbilical cord bloodderived mesenchymal stem cells in a cirrhotic rat model. Liver Int 29: 898-909, 2009.
25. Aguayo-Mazzucato $\mathrm{C}$ and Bonner-Weir S: Stem cell therapy for type 1 diabetes mellitus. Nat Rev Endocrinol 6: 139-148, 2010.

26. Wang HS, Shyu JF, Shen WS, Hsu HC, Chi TC, Chen CP, Huang SW, Shyr YM, Tang KT and Chen TH: Transplantation of insulin producing cells derived from umbilical cord stromal mesenchymal stem cells to treat NOD mice. Cell Transplant (In press).

27. Kadam S, Muthyala S, Nair P and Bhonde R: Human placentaderived mesenchymal stem cells and islet-like cell clusters generated from these cells as a novel source for stem cell therapy in diabetes. Rev Diabet Stud 7: 168-182, 2010.

28. Zhang Y, Jayaprakasam B and Seeram NP: Insulin secretion and cyclooxygenase enzyme inhibition by cabernet sauvignon grape skin compounds. J Agric Food Chem 52: 228-233, 2004.

29. Choi YK, Kim TK and Kim CJ: Activation of the intrinsic mitochondrial apoptotic pathway in swine influenza virusmediated cell death. Exp Mol Med 38: 11-17, 2006.

30. Hanson RW and Reshef L: Regulation of phosphoenolpyruvate carboxykinase (GTP) gene expression. Annu Rev Biochem 66: 581-611, 1997.

31. Nolte W, Hartmann H and Ramadori G: Glucose metabolism and liver cirrhosis. Exp Clin Endocrinol Diabetes 103: 63-74, 1995.

32. Petrides AS, Vogt C and Schulze-Berge D: Pathogenesis of glucose intolerance and diabetes mellitus in cirrhosis. Hepatology 19: 616-627, 1994.

33. Selberg O, Burchert $\mathrm{W}$ and vd Hoff $\mathrm{J}$ : Insulin resistance in liver cirrhosis. Positron-emission tomography scan analysis of skeletal muscle glucose metabolism. J Clin Invest 91: 1897-1902, 1993.

34. Vannini P, Forlani G and Marchesini G: The euglycemic clamp technique in patients with liver cirrhosis. Horm Metab Res 16: 341-343, 1984.

35. Kahn CR: Insulin resistance, insulin insensitivity, and insulin unresponsiveness: a necessary distinction. Metabolism 27: 1893-1902, 1978

36. Hess D, Li L, Martin M, Sakano S, Hill D, Strutt B, Thyssen S, Gray DA and Bhatia M: Bone marrow-derived stem cells initiate pancreatic regeneration. Nat Biotechnol 21: 763-770, 2003.

37. Czech MP and Corvera S: Signaling mechanisms that regulate glucose transport. J Biol Chem 274: 1865-1868, 1999.

38. Lange AJ, Argaud D and el-Maghrabi MR: Isolation of a cDNA for the catalytic subunit of rat liver glucose-6-phosphatase: regulation of gene expression in FAO hepatoma cells by insulin, dexamethasone and cAMP. Biochem Biophys Res Commun 201: 302-309, 1994

39. Nordlie RC, Foster JD and Lange AJ: Regulation of glucose production by the liver. Annu Rev Nutr 19: 379-406, 1999.

40. Haber BA, Chin S and Chuang E: High levels of glucose-6phosphatase gene and protein expression reflect an adaptive response in proliferating liver and diabetes. J Clin Invest 95: 832-841, 1995.

41. Rosella G, Zajac JD and Baker L: Impaired glucose tolerance and increased weight gain in transgenic rats overexpressing a non-insulin-responsive phosphoenolpyruvate carboxykinase gene. Mol Endocrinol 9: 1396-1404, 1995. 